LAWRENCE LIVERMORE NATIONAL LABORATORY

\title{
Computation of Hypersonic Flow about Maneuvering Vehicles with Changing Shapes
}

F. F. Felker

V.M. Castillo

R.M. Ferencz

February 19, 2004 


\section{Disclaimer}

This document was prepared as an account of work sponsored by an agency of the United States Government. Neither the United States Government nor the University of California nor any of their employees, makes any warranty, express or implied, or assumes any legal liability or responsibility for the accuracy, completeness, or usefulness of any information, apparatus, product, or process disclosed, or represents that its use would not infringe privately owned rights. Reference herein to any specific commercial product, process, or service by trade name, trademark, manufacturer, or otherwise, does not necessarily constitute or imply its endorsement, recommendation, or favoring by the United States Government or the University of California. The views and opinions of authors expressed herein do not necessarily state or reflect those of the United States Government or the University of California, and shall not be used for advertising or product endorsement purposes.

This work was performed under the auspices of the U.S. Department of Energy by University of California, Lawrence Livermore National Laboratory under Contract W-7405-Eng-48.

\section{LDRD Auspices Statement}

This research is funded by the Laboratory Directed Research and Development (LDRD) Program at Lawrence Livermore National Laboratory (LLNL) under project 03-ERD-026 The LDRD Program is mandated by Congress to fund laboratory-initiated, long-term research and development (R\&D) projects in support of the DOE and national laboratories' mission areas. The Director's Office LDRD Program at LLNL funds creative and innovative R\&D to ensure the scientific vitality of the Laboratory in mission-related scientific disciplines. 


\title{
Computation of Hypersonic Flow about Maneuvering Vehicles with Changing Shapes
}

\author{
F.F. Felker, V. M. Castillo and R.M. Ferencz
}

Vehicles moving at hypersonic speeds have great importance to the National Security. Ballistic missile re-entry vehicles (RV's) travel at hypersonic speeds, as do missile defense intercept vehicles. Despite the importance of the problem, no computational analysis method is available to predict the aerodynamic environment of maneuvering hypersonic vehicles, and no analysis is available to predict the transient effects of their shape changes. The present state-of-the-art for hypersonic flow calculations typically still considers steady flow about fixed shapes. Additionally, with present computational methods, it is not possible to compute the entire transient structural and thermal loads for a re-entry vehicle.

The objective of this research is to provide the required theoretical development and a computational analysis tool for calculating the hypersonic flow about maneuvering, deforming RV's. This key enabling technology will allow the development of a complete multi-mechanics simulation of the entire RV flight sequence, including important transient effects such as complex flight dynamics. This will allow the computation of the as-delivered state of the payload in both normal and unusual operational environments. This new analysis capability could also provide the ability to predict the nonlinear, transient behavior of endo-atmospheric missile interceptor vehicles to the input of advanced control systems.

Due to the computational intensity of fluid dynamics for hypersonics, the usual approach for calculating the flow about a vehicle that is changing shape is to complete a series of steady calculations, each with a fixed shape. However, this quasi-steady approach is not adequate to resolve the frequencies characteristic of a vehicle's structural dynamics. Our approach is to include the effects of the unsteady body shape changes in the finite-volume method by allowing for arbitrary translation and deformation of the control volumes. Furthermore, because the Eulerian computational mesh for the fluid domain must be attached to the vehicle as it undergoes potentially high accelerations, that mesh must be viewed in a non-inertial coordinate frame. The usual conservation-law form of the fluid dynamic governing equations must be augmented. This approach thus requires the derivation of a significantly new numerical formulation, especially to incorporate a modern flux-splitting methodology as needed for numerical stability and accuracy.

Project accomplishments were truncated by the departure of the Principal Investigator from the Laboratory midway through FY03. However much of the numerical formulation was conceptualized and derived. That effort is documented by the HyperFlow Theory Manual (UCRL-TR-202562) which represents a significant, tangible product of the modest funding actually expended. This initial effort concentrated on the deforming, noninertial mesh considerations in the context of inviscid flows. We are making contacts in the academic community seeking an independent review of this work and anticipate a 
future publication. With that baseline established, the numerical formulation must be augmented to consider effects of viscosity and other "diffusive" mechanisms. Reactive chemistry is another component that must be added to achieve our eventual goals for hypersonic flow simulation.

The implementation of this new methodology is now being supported with programmatic effort. A computer code is being written within the Method Development Group's Diablo framework and was "born parallel". It takes advantage of some of the sophisticated features of Fortran95 to pass data structures in an efficient manner. A steady inviscid capability with explicit time integration has been prototyped. To demonstrate the accuracy of the code, we use a series of verification tests including simulations of a shock tube and simulations of various shapes in a hypersonic flow field. The shock tube simulation results show extremely sharp shock wave profiles. These demonstrate the advantage of using the flux-splitting method. Test cases simulating a wedge shape in various flow fields up to Mach 20 show good agreement with known results for the shock angles.

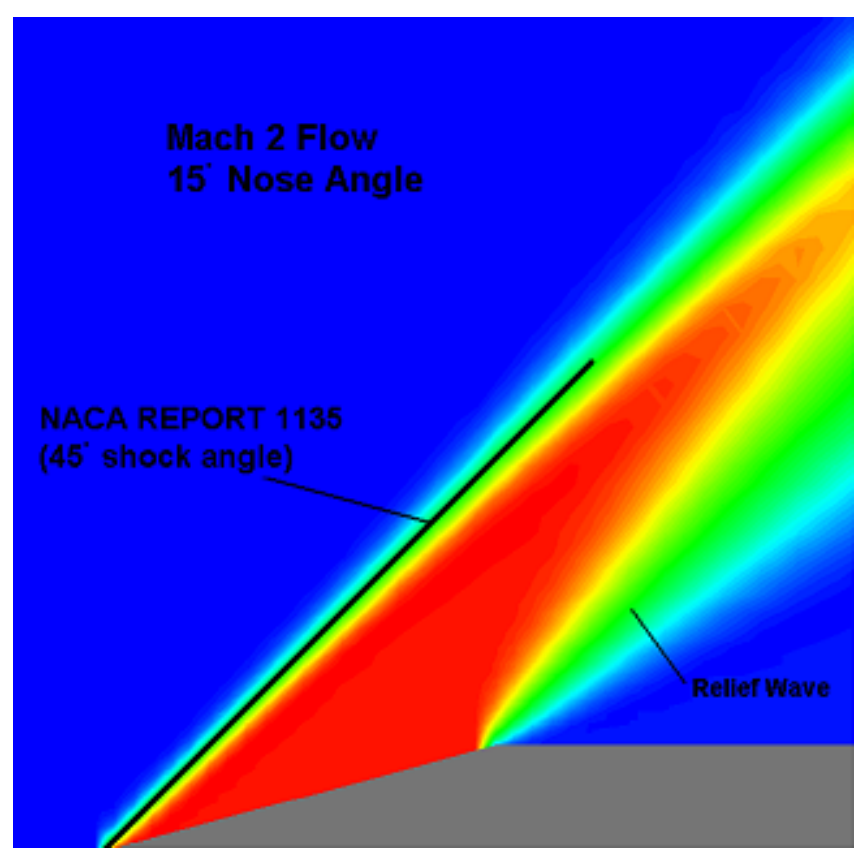

Calculated pressure of a low Mach number flow showing the predicted shock angle and relief wave. 